\title{
The impacts of market reform on the market penetration of natural gas-fired electricity and renewable energy in China
}

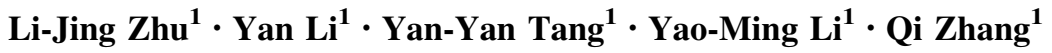

Received: 21 April 2017/Published online: 7 September 2017

(C) The Author(s) 2017. This article is an open access publication

\begin{abstract}
Natural gas-fired electricity (NGFE) is expected to play a more important role in the future due to its characteristics of low pollution, high efficiency and flexibility. However, its development in China is impeded by its high regulation price compared with coal power. Market reform is therefore of vital importance to promote the penetration of NGFE. The objective of this study is to analyze the impacts of market reform and the renewable electricity (RE) subsidy policy on the promotion of NGFE and RE. A dynamic game-theoretic model is developed to analyze the interaction among the NG supplier, the power sector and the power grid. Three scenarios are proposed with different policies, including a fixed regulation price of NG and electricity, real-time pricing (RTP) of NG and electricity, and subsidy targeted at RE. The results show that: (1) market reform can sharply decrease the NG price and consequently promote the development of NGFE and RE; (2) subsidy targeted at RE not only promotes the penetration of NGFE and RE, but also increases the utilization ratio of renewables significantly; (3) market reform and the subsidy also enhance consumers' welfare by reducing their power consumption expenditure.
\end{abstract}

Keywords Natural gas-fired electricity · Renewable electricity · Real-time pricing - Market reform - Gametheoretic model

Qi Zhang

zhangqi@cup.edu.cn; zhangqi56@tsinghua.org.cn

1 Academy of Chinese Energy Strategy, China University of Petroleum-Beijing, Beijing 102249, China

Edited by Xiu-Qin Zhu

\author{
Abbreviations \\ NGFE Natural gas-fired electricity \\ CFE Coal-fired electricity \\ RE Renewable energy generated electricity
}

Indices

$t \quad$ Hours

Gas (subscript) Natural gas-fired electricity

Coal (subscript) Coal-fired electricity

\section{Parameters}

$G P \quad$ Price of $\mathrm{NG}$ for power generation, $\mathrm{RMB} / \mathrm{m}^{3}$

$C P \quad$ Price of coal for power generation, $\mathrm{RMB} / \mathrm{kg}$

$G C \quad$ Unit production cost of $\mathrm{NG}, \mathrm{RMB} / \mathrm{m}^{3}$

FIXG Unit fixed generation cost of $\mathrm{NG}, \mathrm{RMB} /(\mathrm{kW} \mathrm{h})$

FIXC Unit fixed generation cost of coal, $\mathrm{RMB} /(\mathrm{kW} \mathrm{h})$

FIXR Unit fixed generation cost of renewable energy, $\mathrm{RMB} /(\mathrm{kW} \mathrm{h})$

RAMP Ramp rate when power generation changes in consecutive hours, $\%$

ECEG Energy conversion efficiency of NG, $(\mathrm{kW} \mathrm{h}) / \mathrm{m}^{3}$

ECEC Energy conversion efficiency of coal, $(\mathrm{kW} \mathrm{h}) / \mathrm{kg}$

$R T D \quad$ Real-time demand, $\mathrm{kW}$

$\overline{N G} \quad$ Production capacity of NG supplier, $\mathrm{m}^{3}$

$\overline{E G} \quad$ Production capacity of NG power generator, $\mathrm{kW}$

$\overline{E C} \quad$ Production capacity of coal power generator, $\mathrm{kW}$

$\overline{E R} \quad$ Production capacity of renewable energy generator, $\mathrm{kW}$

\section{Variables}

gs

ers

egs
NG supply, $\mathrm{m}^{3}$

Supply of electricity generated by renewable energy, $\mathrm{kW}$

Supply of electricity generated by NG, kW 
ecs Supply of electricity generated by coal, $\mathrm{kW}$

ed Electricity demand of power grid, $\mathrm{kW}$

$\alpha, \beta, \theta G P, E P \quad$ Lagrange multiplier

\section{Introduction}

In order to tackle climate change issues, the Chinese government has a target for China to achieve a peaking of $\mathrm{CO}_{2}$ emissions around 2030 with best efforts to make the peak earlier (as early as 2020) and lower emissions intensity per unit of GDP by 60\%-65\% from 2005 levels (The State Council Information Office of the People's Republic of China 2015). Nevertheless, coal still contributes to the majority of electricity generation in China due to its economic advantage over natural gas (NG) and renewable energy (RE). In 2012, nearly half of the total carbon emissions were produced by coal-fired power generation in China (NEA 2013). It is of vital importance to implement radical actions to promote a low carbon system with NG and RE to shift away from the coal-dominated energy structure (Liu et al. 2014).

Natural gas-fired electricity (NGFE) has attracted great attention recently. NG is identified as an important energy source for electricity generation due to its characteristics of low pollution and high combustion efficiency (Muller and Mendelsohn 2009). Moreover, natural gas-fired power plants have a competitive edge in peak shaving ability due to their high ramp-up and ramp-down rates (Liu et al. 2015). With the operation of gas pipelines and the construction of LNG receiving terminals, the development of NG has achieved prominent progress in recent years. The Chinese government has proposed a national energy strategy to boost the ratio of NG in total energy consumption to at least $10 \%$ by 2020 (GOSC 2014). However, NGFE occupied merely $3 \%$ of total power generation in 2015 , which indicates that China is still in its initial stage of developing NGFE. The high price of NG under regulation is considered as the major barrier for NGFE penetration. The fuel cost of natural gas-fired power is much higher than that of coal power, resulting in a financial loss in most natural gas-fired power plants (Dong et al. 2012; Zhai and Rubin 2013). Apparently, the current pricing regime fails to provide enough incentives for NGFE penetration. Consequently, it is critical to conduct a market-oriented reform of NG pricing in China.

During the process of supply-side reform, renewable energy offers an important alternative to coal as a source of energy for electricity generation in China (Mcelroy et al. 2009; Puller and West 2013). Thanks to the abundant resources and promotion policies such as subsidies, China's renewable energy industries, especially photovoltaic
(PV) power and wind power, have experienced dramatic expansion in recent years. Specifically, China's cumulative grid feed-in installed capacity of wind power and PV power reached $172.18 \mathrm{GW}$ in 2015 , which has taken a leading position in the world. However, the phenomenon of low utilization ratio of renewable electricity is a serious problem. Renewable energy generation is both variable and uncertain because the energy production is determined by the underlying meteorological factors such as wind speed and insolation. Consequently, the abundant renewable energy is curtailed to keep a real-time balance between load and generation in the power system. The total curtailment electricity for intermittent renewables reached $38,600 \mathrm{GWh}$ in 2015 , which means the utilization ratio of renewable electricity only accounts for $0.7 \%$ of the total generated electricity. China's renewable energy policies must be modified to incentivize the actual delivered renewable electricity (RE), not the installed capacity (Lam et al. 2013).

The development of RE depends on not only the subsidy policy, but also the backup function provided by a large scale of NGFE, because renewable energy is intermittent and the fluctuations need to be absorbed by flexible power sources like NGFE (Kok et al. 2015; Zhang et al. 2013). When large-scale wind power and PV power are integrated into the grid, the operation of the power system can be influenced in terms of safety and stability (Hui et al. 2017). Consequently, it requires a high level of peak regulation, which cannot be satisfied when coal-fired electricity (CFE) dominates the electricity generation. NGFE can solve this problem with its high ramp-up and rampdown rates (Levi 2013). Apart from the renewables, another cause for the deterioration of the peak shaving pressure is the unstable power consumption. From the perspective of demand-side reform, the large peak-valley difference in electricity load indicates that the effect of time-of-use pricing is ineffective in the setting of tariffs. In comparison, real-time pricing (RTP) of the electricity is widely used in the world to reflect the true market value of electricity.

Many scholars have proved the necessity of NGFE either from the perspective of stimulating NG consumption or improving power system efficiency. Li et al. (2011) showed that the development of NGFE is an efficient way to stimulate NG consumption and increase the share of NG in China's energy mix. Hu et al. (2013) found that NGFE could be used as a resource in China with multiple benefits such as lower total costs and improved power system efficiency for coal generators. Many studies focused on forecasting the development of NGFE in China and analyzing China's promotion policies to stimulate NGFE. Xiao et al. (2016) utilized system dynamics methodology to evaluate the development pattern and constraints in NGFE 
development in China. They estimated that the NGFE installed capacity would reach $236 \mathrm{GW}$ by 2030 , with an average annual growth rate of about $10 \%$ in 2005-2030. Kahrl et al. (2013) found that NG is already cost-competitive for peaking applications in China's power system, whereas NG load following and base load generation are not currently cost-competitive. They therefore indicated that reforms in the NG pricing mechanism, a carbon price, and reforms in electricity wholesale pricing could make NG more competitive as a baseload power source. However, most of previous research estimated the NG price for generation based on the regulated pricing mechanism and few considered the development of NGFE under marketoriented NG price reforms.

The NG price reforms in China have attracted a great deal of attention recently (Hu and Dong 2015; Paltsev and Zhang 2015; Dong et al. 2017). NG prices in China have been set on a highly regulated cost-plus approach to protect consumers. Since 2011, China has adopted the NG netback market value approach, connecting the price with international fuel oil and liquid petroleum gas prices (Paltsev and Zhang 2015). Since April 1, 2015, direct-supply gas prices have been released, and the stock gas prices and incremental gas prices have been unified (Hu and Dong 2015). The price unification indicates a new stage of development for NG pricing reform in China. However, there is still a long way to go before the price is ultimately determined based on the interaction of supply and demand. Moreover, the existing pricing system leads to a higher NG prices in industry and power sectors than in the residential sector (Dong et al. 2017), which restrains the gas demand of the industry and power sectors. Fan et al. (2015) demonstrated that after the NG price reform, the fuel cost of NGFE increased by $26 \%-44 \%$, and the ratio of fuel costs between NGFE and CFE in China is almost around 2-2.5. The high fuel cost severely limited the development of NGFE in China. Hence, it is of vital importance to consider the demand-side dynamics of NG and establish a complete market-oriented NG pricing system. Experiences from the USA where NG prices are determined by the interaction of supply and demand (Paltsev and Zhang 2015), and the EU where some prices are still linked to oil (Percebois 1999), offer an illustration of the relative efficiencies of gas pricing mechanisms and the benefits of moving to a more complete market system.

There are a few studies on incentive policies for China's $\mathrm{RE}$ development. The main barrier for RE development in China is its high fixed costs compared to conventional energy (Zhao et al. 2012). Zhao et al. (2013a) showed that the Chinese government's incentive policies have played a crucial role in promoting RE generation. Zhao et al. (2013b) conducted an empirical analysis on the effectiveness of RE policies in promoting RE generation using a large panel dataset. They found that policy effectiveness varies by the type of policy and energy source. Lam et al. (2013) classified the incentive policies for RE in China into four kinds, which are government financial subsidy, technical support, feed-in-tariff policy, and tax incentives. Zhao et al. (2016) reviewed the financial subsidies provided by the Chinese government to support the development of RE. Different subsidy standards have been formulated for different sectors, such as wind power equipment manufacturers, grid-connected PV power projects, PV power demonstration buildings and user-side PV power projects. They found that the subsidies have significant positive impacts on the development of the RE sector. The existing studies are mainly focused on the effectiveness of different incentive policies for RE, few aimed to analyze the development of NGFE and RE with consideration of the effects of their interaction.

Recently, game theory has been widely adopted as a key research tool in the power market. Game theory is a formal analytical and conceptual framework with a set of mathematical tools enabling the study of complex interactions among independent rational players (Saad et al. 2012; Tian et al. 2017). It has been applied to study the demand response of both the electricity market and end users (Nekouei et al. 2015), the optimization of time-of-use electricity pricing strategies (Yang et al. 2013), solutions to accommodate high penetration of intermittent renewable energy resources and emerging smart grid technologies ( $\mathrm{Su}$ and Huang 2014), and the impact of the response capability of smart home consumers on distributed photovoltaic penetration (Wang et al. 2017) among other applications. However, game theory has seldom been used in studying the penetration of NGFE in competition with CFE.

This study aims to analyze the impact of pricing reform and the RE-targeted subsidy policy on the promotion of NGFE and RE. A real-time pricing mechanism is applied to both the NG market and power market considering demand response from end users. A game theory model is proposed based on a multi-agent system, and different scenarios of market reform are studied using the model, specifically real-time pricing and renewable subsidies.

The main contributions of the study include (1) market deregulation for NG and electricity are jointly proposed and generation planning is investigated dynamically and flexibly; (2) a general game theory model is proposed to formulate the interaction between the NG market and electricity market under the strict requirement of market clearing; (3) managerial insights for the Chinese government to promote the share of NGFE and RE is addressed; the outcomes can also provide relevant insights and suggestions for other countries.

The remainder of this paper is organized as follows: Sect. 2 describes the methodology which formulates the 
interactive relationship among the three participants, the scenario designs and data input are also depicted in this section. Section 3 specifically compares and discusses the results of each scenario with a series of real-world data and sensitivity analysis is also presented in this section. Section 4 summarizes the paper and draws out the conclusions.

\section{Methodology}

\subsection{Model framework}

The model framework is shown in Fig. 1. In the presented model, there are three participants, which are the NG supplier, the power sector and the power grid. In the power sector, electricity is generated from coal, NG and renewable energy. Renewable energy here includes wind and PV energy without fuel cost.

In practice, the fixed regulation gas price and electricity price are used in the electricity generation system. In order to analyze the impact of market reform, we consider realtime pricing for both NG and electricity. The real-time price is obtained through the market clearing conditions between the NG supplier and the power sector as well as the power sector and power grid, respectively. The demand for NG comes from the power sector's operation of gas power plants to generate electricity. The demand for electricity is from the power grid's purchase. Principally, the NG supplier makes decisions on the sale volume of NG to maximize its total profit, the power sector makes decision on the purchase volume of NG and sale volume of electricity to maximize its total profit, while the grid makes decision on the purchase volume of electricity to meet consumer demand and to minimize the power expenses. When the sale volume and purchase volume of NG are equal, the market clearing NG price is formed and correlated with the decision variables of trading NG volume. Similarly, the market clearing electricity price can be obtained when the sale volume of electricity matches its purchase volume. In this situation, the NG supplier prefers a relatively high price of NG, the power sector prefers a lower price of NG and relatively high price of electricity, while the end consumers prefer a relatively low price of electricity. In other words, there are conflicts among the market participants and the game is thus formed.

\subsection{Modeling the game relations among the NG supplier, the power sector and the power grid}

The game relations between the NG supplier and the power sector will result in a dynamic balance between supply and demand according to the real-time gas price, when the Nash equilibrium is achieved. The objective of the NG supplier is described as Eq. (1). However, the constraint is that the maximum NG supply should not exceed the production capacity of the NG supplier, as shown in Eq. (2).

$$
\begin{array}{ll}
\operatorname{Max} & \sum_{t} g s_{t}\left(G P_{t}-G C\right) \\
\text { s.t. } & g s_{t} \leq \overline{N G}\left(\alpha_{t}\right)
\end{array}
$$

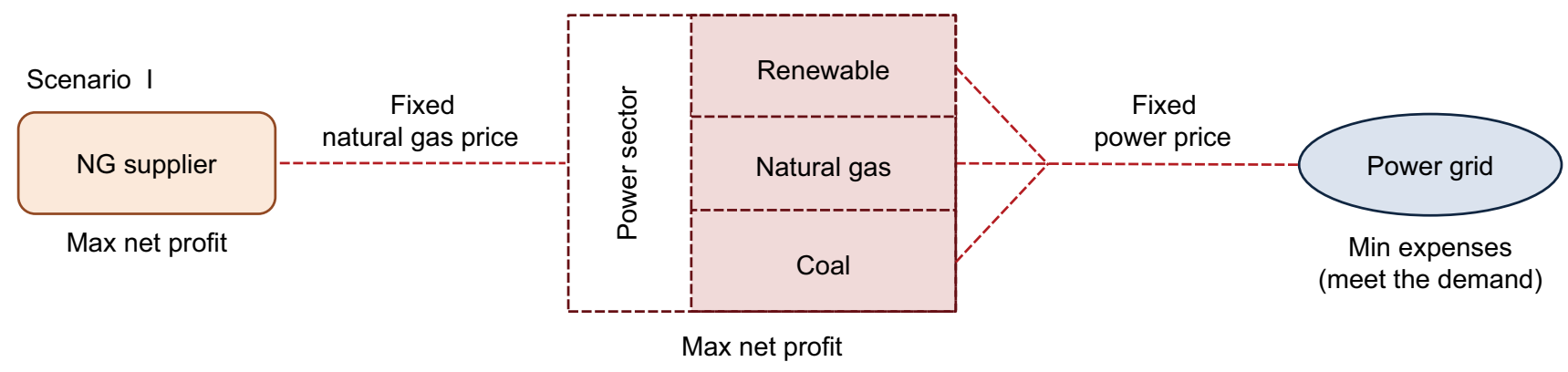

Scenario II \& Scenario III (RE subsidy)
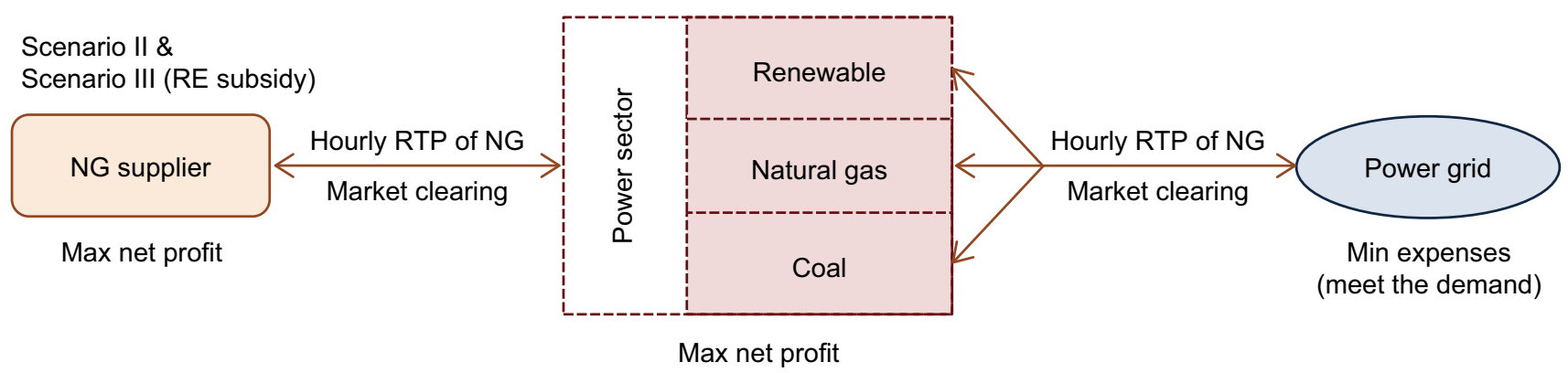

Fig. 1 Structure of the target system 
where $g s_{t}$ is the supply of NG at time $t ; G P_{t}$ is the NG price used for power generation at time $t ; G C$ is the unit production cost of NG, which does not vary with time during 1 day.

As for the power sector, its net profit is expressed as the revenue from selling electricity to the power grid subtracting the generation cost from NG, coal and renewable energy. The generation cost includes both variable and fixed costs. So the objective is described as:

$$
\begin{aligned}
\operatorname{Max} & \left\{\sum_{t}\left(e r s_{t}+e g s_{t}+e c s_{t}\right) \times E P_{t}\right. \\
& -\left[\sum_{t}\left(\frac{e g s_{t}}{E C E G} \times G P_{t}\right)+\sum_{t}\left(F I X G \times e g s_{t}\right)\right] \\
& -\left[\sum_{t}\left(\frac{e c s_{t}}{E C E C} \times C P_{t}\right)+\sum_{t}\left(F I X C \times e c s_{t}\right)\right] \\
& \left.-\sum_{t}\left(F I X R \times e r s_{t}\right)\right\}
\end{aligned}
$$

The generation using different kinds of fuel cannot exceed their upper bounds as shown in Eqs. (4)-(6). Additionally, generation ramp rate constraints (7)-(10) should be satisfied.

$$
\begin{aligned}
& \text { s.t. } \quad e g s_{t} \leq \overline{E G} \cdot 1 h \quad\left(\beta_{1 t}\right) \\
& e c s_{t} \leq \overline{E C} \cdot 1 h \quad\left(\beta_{2 t}\right) \\
& \operatorname{ers}_{t} \leq \overline{E R_{t}} \cdot 1 h \quad\left(\beta_{3 t}\right) \\
& \operatorname{egs}_{t}-e g s_{t-1} \leq R A M P_{\text {gas }} \cdot \overline{E G} \cdot 1 h \quad\left(\beta_{4 t}\right) \\
& e c s_{t}-e c s_{t-1} \leq R A M P_{\text {coal }} \cdot \overline{E C} \cdot 1 h \quad\left(\beta_{5 t}\right) \\
& \text { egs }_{t-1}-e g s_{t} \leq R A M P_{\text {gas }} \cdot \overline{E G} \cdot 1 h \quad\left(\beta_{6 t}\right) \\
& \text { ecs }_{t-1}-e c s_{t} \leq R A M P_{\text {coal }} \cdot \overline{E C} \cdot 1 h \quad\left(\beta_{7 t}\right)
\end{aligned}
$$

where $e r s_{t}, e g s_{t}$ and $e c s_{t}$ represent the supply of electricity generated by renewable energy, NG and coal, respectively; $E P_{t}$ is the electricity price; $E C E G$ and $E C E C$ are the energy conversion efficiency of $\mathrm{NG}$ and coal, respectively; $G P_{t}$ and $C P_{t}$ are the fuel price of NG and coal; the fuel price of renewables is zero; FIXG, FIXC and FIXR stand for the unit fixed generation cost of NG, coal and renewable; $\overline{E G}$ and $\overline{E C}$ are the fixed capacity of NG power plants and coalfired power plants; $\overline{E R_{t}}$ is a changing restriction of the upper limit because the dynamic meteorological factors will affect the PV radiation and wind speed. In other words, the maximum available capacity of renewable is not the same at different times even in the same day; $R A M P_{\text {gas }}$ and $R A M P_{\text {coal }}$ are the ramp rate of NG power plants and coalfired power plants when power generation changes in consecutive hours.
The NG price is determined by the supply and demand through the market clearing condition, as shown in Eq. (11).

$g s_{t}=\frac{e g s_{t}}{E C E G} \quad\left(G P_{t}\right)$

The power grid purchases electricity from the power sector to pursue its own minimum total cost, which is shown in Eq. (12) and also to meet at least $95 \%$ of the consumers' demand.

$\operatorname{Min} \sum_{t}\left(e d_{t} \times E P_{t}\right)$

s.t. $\quad \sum_{t} e d_{t} \geq \sum_{t} R T D_{t} \quad\left(\theta_{1 t}\right)$

$e d_{t} \geq 0.95 R T D_{t} \quad\left(\theta_{2 t}\right)$

$e d_{t} \leq 1.05 R T D_{t} \quad\left(\theta_{3 t}\right)$

where $e d_{t}$ is the electricity demand of the power grid at time $t$; $R T D_{t}$ is the real-time demand of end users. End users can adjust their demand within the range of 5\% after the implementation of RTP mechanism. The real-time electricity price is determined by the supply and demand of electricity through the market clearing condition, as shown in Eq. (16).

$e g s_{t}+e c s_{t}+e r s_{t}=e d_{t} \quad\left(E P_{t}\right)$

\subsection{Scenario design}

Three scenarios are proposed and compared to demonstrate the impact of market reform and subsidy on the penetration of NGFE and RE. Table 1 lists the details of the scenarios.

\subsubsection{Scenario I: regulated NG and electricity market}

Scenario I is designed based on the current situation that both the electricity price and NG price are regulated. It is used as a benchmark scenario to provide the baseline for comparing other scenarios and indicating the impacts of different factors for the promotion of NGFE and RE.

\subsubsection{Scenario II: deregulated NG and electricity market}

In this scenario, the hourly RTP is applied in both NG and electricity markets. The hourly RTP electricity price is generated in the game between the power sector and the power grid. While the hourly RTP gas price is determined by the intersection of hourly supply-demand balance of NG between the power sector and the NG supplier.

\subsubsection{Scenario III: deregulated NG and electricity market with renewable energy subsidy}

In this scenario, a deregulated market is also investigated. Meanwhile, the government will subsidize the power sector 
Table 1 Scenario proposal and setting

\begin{tabular}{llcl}
\hline Scenario set & Pricing mechanism & Renewable subsidy \\
\cline { 2 - 4 } & NG price & Electricity price & No \\
\hline Scenario I & Regulated by local government & Regulated by central government (NDRC) & No \\
Scenario II & Decided by supply and demand (market clearing) & Yes \\
Scenario III & Decided by supply and demand (market clearing) & \\
\hline
\end{tabular}

if they use renewable energy for generation. It is assumed that subsidy for the renewable electricity is $0.17 \mathrm{RMB}$ per kilowatt hour.

\subsection{Data input}

In this dynamic analysis, the hourly electricity consumption of one typical day of 2015 in China was chosen and the demand curve is shown in Fig. 2. The peak load appears at noon, and the lowest load appears during nighttime.

The NG price is assumed as $1.9 \mathrm{RMB} / / \mathrm{Nm}^{3}$ (Gasonline 2017) on the average level, and the electricity price is 0.56 $\mathrm{RMB} /(\mathrm{kW} \mathrm{h})$ through the weighted average of the data on three kinds of users shown in Table 2 . The average coal price is set as 0.52 RMB/kg (Real-time Coal Trade Price 2017).

The production capacity for the NG supplier is $12,000,000 \mathrm{~m}^{3}$ per hour. The total installed capacity for NG power generators, coal power generators and renewable energy generators are 64, 986 and $164 \mathrm{GW}(128 \mathrm{GW}$ for wind power and $37 \mathrm{GW}$ for PV power), respectively. As for the ramp rate, $R A M P_{\text {coal }}$ and $R A M P_{\text {gas }}$ are $3 \%$ and $90 \%$ per hour for CFE and NGFE, respectively. The above data were acquired from the National Bureau of Statistics of China (National Bureau of Statistics of China 2015).

As for the energy conversion efficiency, this was obtained from the data shown in Table 3. The fixed generation costs for $\mathrm{CFE}$ and $\mathrm{NGFE}$ are $F I X C=0.1359$ $\mathrm{RMB} /(\mathrm{kW} \mathrm{h})$ and $F I X G=0.1041 \mathrm{RMB} /(\mathrm{kW} \mathrm{h})$, which were calculated based on Eqs. (17) and (18) as well as data from the International Energy Agency (IEA 2015).

$C A=\frac{R}{1-(1+R)^{-y}} \times C_{M}$

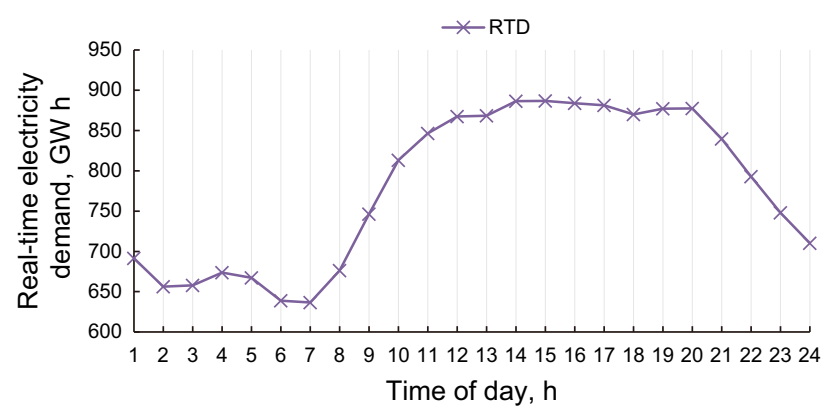

Fig. 2 Hourly electricity consumption during one typical day
$F I X=\frac{C A+C_{M O}}{H}$

where $R$ is the payment rate of capital cost per year; $y$ is the lifetime years of unit; $C_{M}$ refers to the total capital cost of CFE or NGFE during the lifetime years of the unit; $C A$ is the capital cost of the unit per year; $C_{M O}$ is the maintenance and operation cost of CFE or NGFE unit; $H$ is the operational hours of each unit per year.

The fixed generation costs for renewables is FIXR $=0.5$ $\mathrm{RMB} /(\mathrm{kW} \mathrm{h})$ with data from the International Energy Agency (IEA 2015). It is worth noting that this study focused on evaluating the impact of NG price reforms and RE subsidies on the promotion of NGFE and RE, whereas the discrepancies between different renewable resources are not the key points of this study. Therefore, we make a weighted average estimation of the fixed generation cost of the renewable for simplicity of the models. More specifically, the weights are the respective proportions of wind power and PV power in the installed capacity of renewable power. In addition, the shares of renewables in terms of total electricity generation and total installed capacity are relatively small compared to fossil fuels; therefore, most of the current results retain validity when the fixed generation costs from different renewable energy are distinguished.

The parameters utilized in this paper are summarized in Table 4. Based on the above data, the NGFE and RE generations can be optimized by employing the game theory model. This game theory model is a mixed complementarity problem and the PATH solver in the General Algebraic Modeling System (GAMS) is used. GAMS is specifically designed for modeling linear, nonlinear and mixed integer optimization problems and lets users concentrate on modeling by eliminating the need to think about purely technical machine-specific problems such as address calculations, storage assignments, subroutine linkage and input-output and flow control.

\section{Result}

In the present study, the model introduced in Sect. 2 is applied for each scenario based on one typical day's data as shown in Fig. 2. Each participant pursues their own objective and also has to satisfy the end users' electricity 
Table 2 Share of electricity demand and average price of different user types

\begin{tabular}{lll}
\hline User type & Share of electricity demand, \% (Gasonline 2017) & Average electricity price, RMB/(kW h) (Tian et al. 2017) \\
\hline Industrial users & 72.15 & 0.5 \\
Commercial users & 14.96 & 0.95 \\
Residential users & 12.89 & 0.46 \\
\hline
\end{tabular}

Table 3 Fuel consumption of NGFE and CFE

\begin{tabular}{llll}
\hline Fuel type & Heat value & Unit efficiency, \% & Energy conversion efficiency \\
\hline Coal & $5000 \mathrm{kcal} / \mathrm{kg}$ & 42 & $2.439(\mathrm{~kW} \mathrm{~h}) / \mathrm{kg}$ \\
NG & $7476.19 \mathrm{kcal} / \mathrm{m}^{3}$ & 58 & $5.05(\mathrm{~kW} \mathrm{~h}) / \mathrm{Nm}^{3}$ \\
\hline
\end{tabular}

Table 4 Parameters list

\begin{tabular}{llll}
\hline Parameter & Value & Parameter & Value \\
\hline$C P$ & $0.52 \mathrm{RMB} / \mathrm{kg}$ & FIXR & $0.5 \mathrm{RMB} /(\mathrm{kW} \mathrm{h})$ \\
$G P^{*}$ & $1.9 \mathrm{RMB} / \mathrm{Nm}^{3}$ & $E C E G$ & $5.05(\mathrm{~kW} \mathrm{~h}) / \mathrm{Nm}^{3}$ \\
$G C$ & $1.1 \mathrm{RMB} / \mathrm{Nm}^{3}$ & $E C E C$ & $2.439(\mathrm{~kW} \mathrm{~h}) / \mathrm{kg}$ \\
$E P^{*}$ & $0.56 \mathrm{RMB} /(\mathrm{kW} \mathrm{h})$ & $\overline{N G}$ & $12,000,000 \mathrm{~m}^{3}$ \\
$F I X C$ & $0.1359 \mathrm{RMB} /(\mathrm{kW} \mathrm{h})$ & $\overline{E C}$ & $986 \mathrm{GW}$ \\
$F I X G$ & $0.1041 \mathrm{RMB} /(\mathrm{kW} \mathrm{h})$ & $\overline{E G}$ & $64 \mathrm{GW}$ \\
\hline
\end{tabular}

* The parameter value is only for scenario I

demand. We use GAMS to solve the problem and obtain the optimal generation of CFE, NGFE and RE are shown in Figs. 3, 4 and 5 .

In scenario I, the share of CFE, NGFE and RE is $96.9 \%$, $2.7 \%$ and $0.4 \%$, respectively, as shown in Fig. 6. Both the regulated NG price and renewable energy's backup cost stay at a high level, making coal the preferred source, which is the reflection of the current situation. In addition, the installed capacity of NG and renewable energy are rather small compared with the entire users' demand. Therefore, coal certainly should bear the responsibility of guaranteeing the supply of electricity. However, the coal power plants are limited by the ramp rate, which means that their outputs cannot rise fast enough within a short period. Consequently, when the power load experiences the

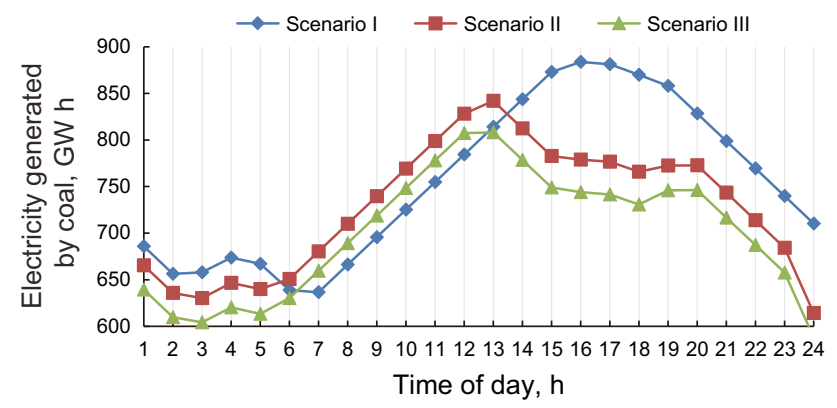

Fig. 3 CFE generation in different scenarios

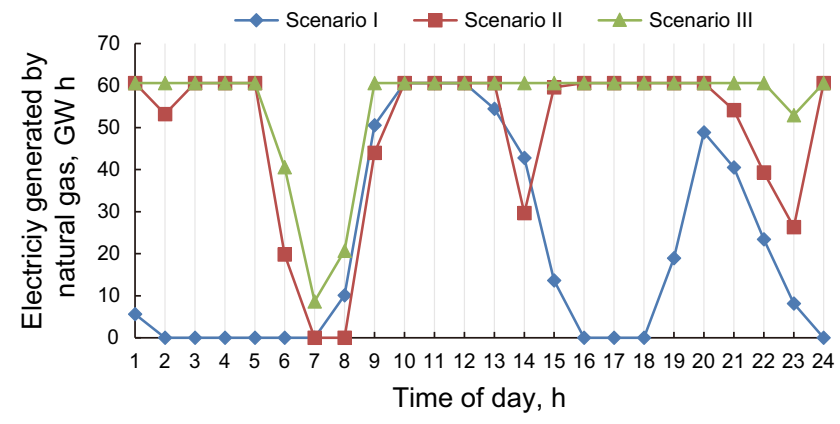

Fig. 4 NGFE generation in different scenarios

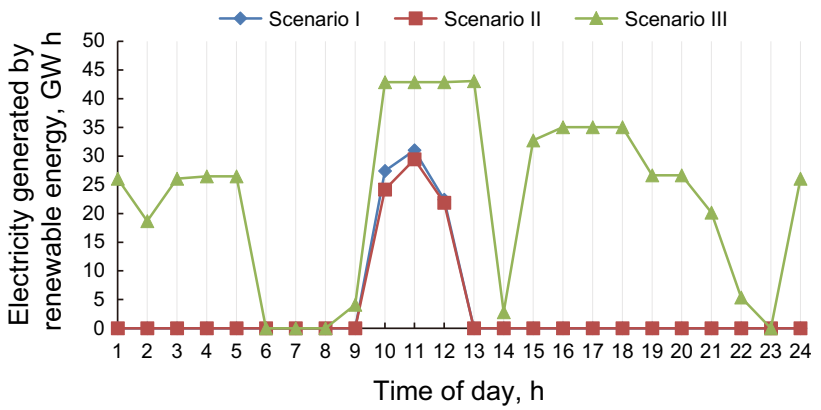

Fig. 5 RE generation in different scenarios

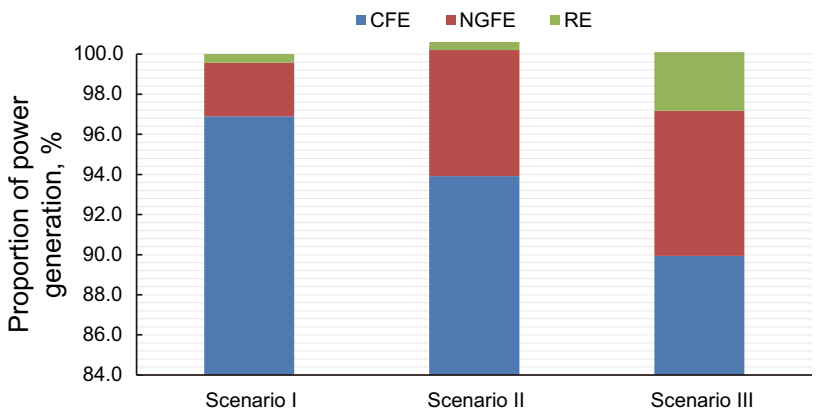

Fig. 6 Share of CFE, NGFE, RE in different scenarios

transition between valley and peak as shown in Fig. 4 corresponding to the period of 8:00-15:00 and 19:00-23:00, NG power plants' advantage of peak shaving 
emerges and gas becomes the supplementary source of electricity generation. However, RE is not economically competitive and the utilization ratio of renewable electricity is only $10.4 \%$ on average.

In scenario II, with the deregulation of the market, the gas price is no longer a fixed value, but rather decided by the game between the NG supplier and the power sector. As shown in Fig. 7, in most of the time, the real-time gas price is much cheaper than that in the regulated market, which is $1.31 \mathrm{RMB} / \mathrm{m}^{3}$ on average. The low cost will make NG more competitive in power generation. It is worth noting that the real-time NG price at 7:00 am is zero. This phenomenon can be explained by Fig. 4 in which the electricity generated by natural gas is zero at 7:00 am. In other words, the power sector does not need any natural gas at the valley time, and hence, the glut causes the zero NG price. As shown in Fig. 4, the production of electricity generated by NG improves compared with scenario I, with the share of NGFE increasing from $2.7 \%$ to $6.3 \%$, meaning the deregulation of NG price is a key factor for promotion of NGFE. Moreover, a deregulated NG price can further lower the electricity price and electricity expenditure. As shown in Fig. 8, the high utilization rate of low cost NG makes the electricity price drop to $0.36 \mathrm{RMB} /(\mathrm{kW} \mathrm{h})$ on average. As shown in Fig. 9, the users' electricity expenditure decreases from 10.47 billion to 6.63 billion per day consequently.

In scenario III, the power sector will be subsidized if it uses renewable energy for generation. It is assumed that before subsidies, the fixed generation cost per kilowatt hour is $0.5 \mathrm{RMB}$. After subsidies, the fixed generation cost per kilowatt hour for renewable generation decreases to 0.33 $\mathrm{RMB}$, which is much cheaper than the fixed unit cost of coal and NG generation. The cost priority makes the utilization of renewable energy improve greatly, and the utilization rate of wind and PV increases. As illustrated in Fig. 5, compared with scenarios I and II, the proportion of RE jumps to $7.1 \%$. When the subsidy is awarded to renewable energy, the production of NGFE is also further increased, as depicted in Fig. 4. The NG price and

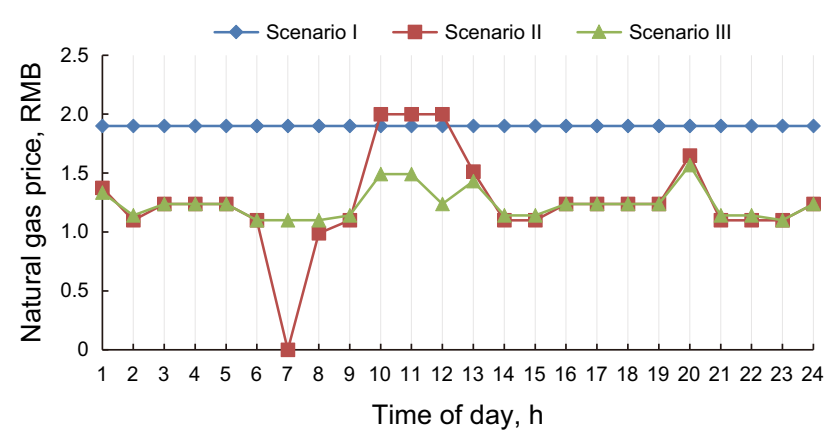

Fig. 7 Real-time NG price in different scenarios

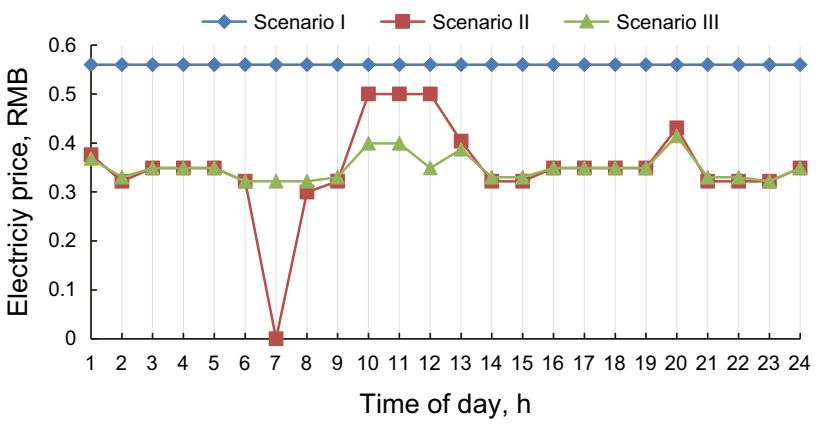

Fig. 8 Real-time electricity price

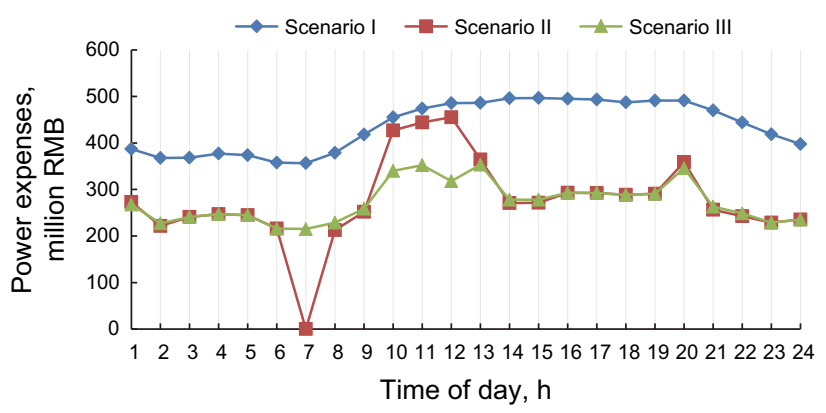

Fig. 9 Electricity expenditure in different scenarios

electricity price in scenario III are more stable compared with scenario II, leading to a decrease of users' expenditure.

Moreover, in order to estimate the efficiency of renewable subsidy, sensitivity analysis is conducted to analyze the impacts of renewable subsidy on the utilization ratio and share of RE in the power generation. Utilization ratio means the proportion of generated RE sold to the grid over its potential output with consideration of weather factors. As shown in Fig. 10, when the renewable subsidy increases from $0.17 \mathrm{RMB} /(\mathrm{kW} \mathrm{h})$ to $0.18 \mathrm{RMB} /(\mathrm{kW} \mathrm{h})$, both of the proportion and utilization ratio of RE jumped from $3.0 \%$ to $4.0 \%$ and $70.0 \%$ to $95.2 \%$, respectively. On the other hand, while the subsidy keeps going up, the power generation mix and renewable utilization ratio is relatively stable, indicating that a renewable subsidy of $0.18 \mathrm{RMB} /(\mathrm{kW} \mathrm{h})$ is most efficient.

As shown in Fig. 11, sensitivity analysis is conducted to study the effect of coal price changes on the share of NGFE and $\mathrm{RE}$ in the power generation. The coal price range is set to be from $0.2 \mathrm{RMB} / \mathrm{kg}$ to $0.7 \mathrm{RMB} / \mathrm{kg}$, which is based on the current coal price information in different areas of China (Real-time Coal Trade Price 2017). Figure 11 shows that when coal price is below $0.45 \mathrm{RMB} / \mathrm{kg}$, the cost advantage of coal leads to a relatively low level of NGFE and RE share in power generation, which are $2 \%$ and nearly $0 \%$, respectively. When coal price is higher than 0.5 $\mathrm{RMB} / \mathrm{kg}$, the cost advantage of coal power generation 


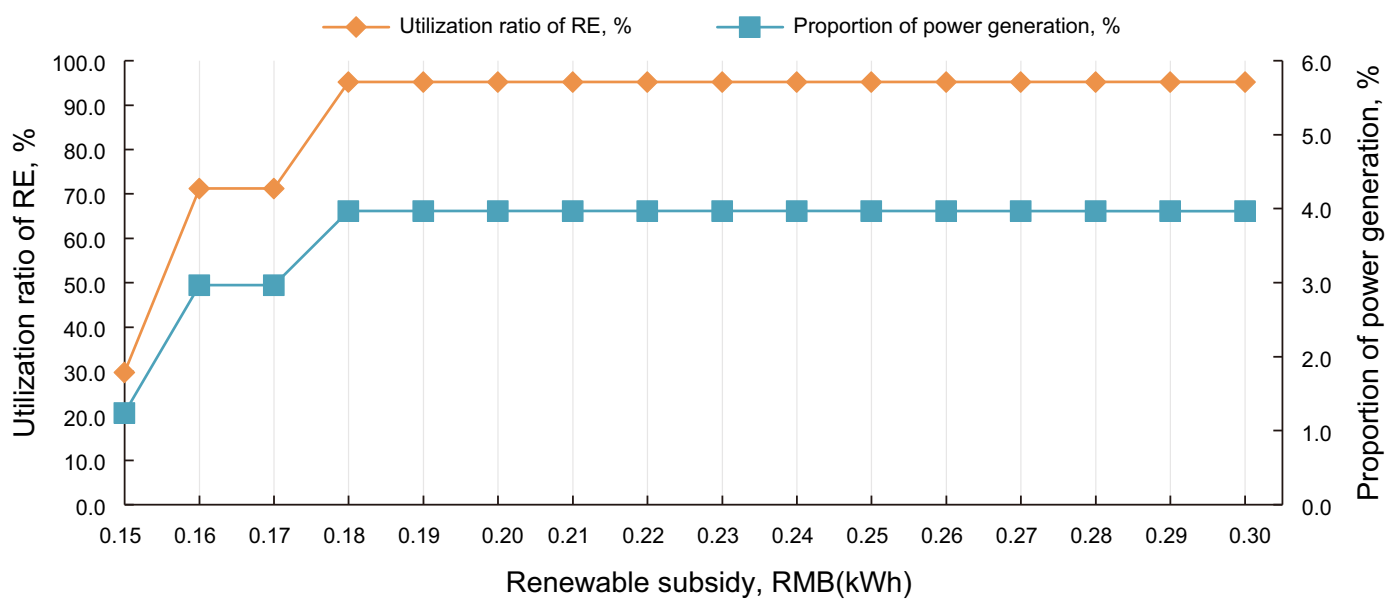

Fig. 10 Impacts of renewable subsidy on utilization ratio and the share of RE in power generation

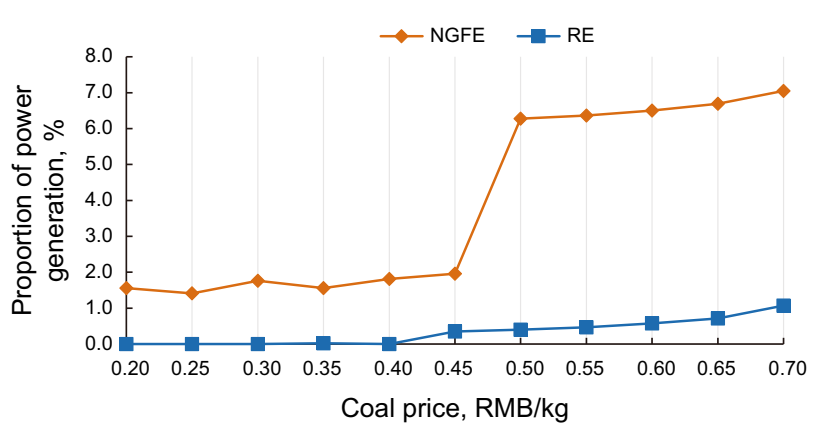

Fig. 11 Impacts of coal price on the share of NGFE and RE in power generation

begins to disappear, whereas the ramp-up advantage of natural gas power generation emerges. The share of NGFE in power generation thus increases significantly, accounting for $6.3 \%$ of the total power generation. As coal price keeps rising, the share of NGFE in power generation continues to increase slightly. Then, the complementarity of NGFE and RE leads to an increasing RE share in power generation. When coal price is $0.7 \mathrm{RMB} / \mathrm{kg}$, the share of $\mathrm{RE}$ in power generation can be as high as $1.1 \%$.

\section{Conclusions}

The slow penetration of NGFE and RE due to price regulation and ineffective subsidy policies has been a serious hindrance for decarbonizing China's energy consumption structure. In the presented study, the impacts of price reform in NG and electricity markets on the promotion of NGFE and RE were studied using a developed game-theoretic model. Specially, the optimal solutions were obtained under market clearing conditions, which are much stricter constraints compared with our previous work.
Three scenarios were analyzed under different policies including market regulation, market deregulation and environmental subsidies targeted at RE. The obtained results show that: (1) The competitiveness of NGFE can be promoted greatly through price reforms. Through deregulation, the NG price decreases from the fixed 1.9 RMB/ $\mathrm{Nm}^{3}$ to the average level of $1.31 \mathrm{RMB} / \mathrm{Nm}^{3}$, which will increase the share of NGFE from $2.7 \%$ to $6.3 \%$; (2) The utilization ratio of renewable energy in power generation can be improved significantly through subsidies targeted at $\mathrm{RE}$. The share of $\mathrm{RE}$ and the utilization ratio can reach $7.1 \%$ and $70.0 \%$, respectively; (3) The deregulation in NG and electricity markets can enhance the users' welfare greatly, with the power price decreasing from $0.56 \mathrm{RMB} /$ $(\mathrm{kW} \mathrm{h})$ to $0.35 \mathrm{RMB} /(\mathrm{kW} \mathrm{h})$ on average, and the total expenditure on power consumption declines correspondingly from 10.47 billion to 6.55 billion RMB per day; (4) A renewable subsidy of $0.18 \mathrm{RMB} /(\mathrm{kW} \mathrm{h})$ is found to be most efficient to improve the power generation mix and $\mathrm{RE}$ utilization ratio, in which the share and utilization ratio of RE reach at $4.0 \%$ and $95.2 \%$, respectively. Our analytical and numerical results imply that a market-oriented NG pricing system and a RE-targeted subsidy to power sectors are of vital importance in promoting the penetration of NGFE and RE.

The present study mainly focused on evaluating the impact of NG price reforms and RE subsidies on the promotion of NGFE and RE; thus, the fixed generation costs from different renewable sources were not distinguished in the model. Future extensions may consider the differences between different renewable energy sources and analyze the effect of RE subsidies for different renewable energy power generations.

Acknowledgements The work was supported by Science Foundation of China University of Petroleum, Beijing (Nos. 2462013YJRC015, 2462014YJRC036). This work was also supported by Ministry of 
Education in China (MOE) Project of Humanities and Social Sciences (Project No. 15YJC630195).

Open Access This article is distributed under the terms of the Creative Commons Attribution 4.0 International License (http://creative commons.org/licenses/by/4.0/), which permits unrestricted use, distribution, and reproduction in any medium, provided you give appropriate credit to the original author(s) and the source, provide a link to the Creative Commons license, and indicate if changes were made.

\section{References}

Dong J, Zhang X, Xu X. Techno-economic assessment and policy of gas power generation considering the role of multiple stakeholders in China. Energy Policy. 2012;48(3):209-21. doi:10. 1016/j.enpol.2012.05.010.

Dong X, Pi G, Ma Z, et al. The reform of the natural gas industry in the PR of China. Renew Sustain Energy Rev. 2017;73:582-93. doi:10.1016/j.rser.2017.01.157.

Fan H, Duan ZF, Shan WG. Status of China's natural gas and power generation development and its prospects. Energy China. 2015;37(2):37-42 (in Chinese).

Gasonline. LNG market-daily LNG price. http://www.gasonline.com. cn/news/LNG/. Accessed 11 Feb 2017.

General Office of the State Council of the People's Republic of China. Energy Development Strategy Plan (2014-2020). 2014. http:// www.gov.cn/zhengce/content/2014-11/19/content_9222.htm. Accessed 19 Jun 2016.

$\mathrm{Hu}$ A, Dong Q. On natural gas pricing reform in China. Nat Gas Ind B. 2015;2(4):374-82. doi:10.1016/j.ngib.2015.09.012.

$\mathrm{Hu} \mathrm{J}$, Kwok G, Wang X, et al. Using natural gas generation to improve power system efficiency in China. Energy Policy. 2013;60(6):116-21. doi:10.1016/j.enpol.2013.04.066.

Hui J, Cai W, Wang C, et al. Analyzing the penetration barriers of clean generation technologies in China's power sector using a multi-region optimization model. Appl Energy. 2017;185: 1809-20. doi:10.1016/j.apenergy.2016.02.034.

International Energy Agency. World Energy Outlook 2015. http:// www.worldenergyoutlook.org/(2015). Accessed 20 Jun 2016.

Kahrl F, Hu J, Kwok G, et al. Strategies for expanding natural gasfired electricity generation in China: economics and policy. Energy Strategy Rev. 2013;2(2):182-9. doi:10.1016/j.esr.2013. 04.006 .

Kok G, Shang K, Yucel S. Impact of electricity pricing policies on renewable energy investments and carbon emissions. 2015. http://dx.doi.org/10.2139/ssrn.2525940.

Lam JCK, Woo CK, Kahrl F, et al. What moves wind energy development in China? Show me the money! Appl Energy. 2013;105(1):423-9. doi:10.1016/j.apenergy.2012.11.067.

Levi M. Climate consequences of natural gas as a bridge fuel. Clim Change. 2013;118(3):609-23. doi:10.1007/s10584-012-0658-3.

Li J, Dong X, Shangguan J, et al. Forecasting the growth of China's natural gas consumption. Energy. 2011;36(3):1380-5. doi:10. 1016/j.energy.2011.01.003.

Liu L, Zong H, Zhao E, et al. Can China realize its carbon emission reduction goal in 2020: from the perspective of thermal power development. Appl Energy. 2014;124:199-212. doi:10.1016/j. apenergy.2014.03.001.

Liu Z, Guan D, Moore S, et al. Climate policy: steps to China's carbon peak. Nature. 2015;522(7556):279-81. doi:10.1038/522279a.

McElroy MB, Lu X, Nielsen CP, et al. Potential for wind-generated electricity in China. Science. 2009;325(5946):1378. www.jstor. org/stable/40301780.
Muller NZ, Mendelsohn R. Efficient pollution regulation: getting the prices right. Am Econ Rev 2009;99(5):1714-39. http://www. jstor.org/stable/25592534.

National Bureau of Statistics of China. National Bureau of Statistics of China. 2015. http://data.stats.gov.cn/index.htm.

National Energy Administration of China. Forecasts of generation capacity and power demand in medium and long-term in China. National Energy Administration. 2013. http://www.nea.gov.cn/ 2013-02/20/c_132180424_2.htm (in Chinese).

Nekouei E, Alpcan T, Chattopadhyay D. Game-theoretic frameworks for demand response in electricity markets. IEEE Trans Smart Grid. 2015;6(2):748-58. doi:10.1109/TSG.2014.2367494.

Paltsev S, Zhang D. Natural gas pricing reform in China: Getting closer to a market system? Energy Policy. 2015;86:43-56. doi:10.1016/j.enpol.2015.06.027.

Percebois J. The gas deregulation process in Europe: economic and political approach. Energy Policy. 1999;27(1):9-15. doi:10. 1016/S0301-4215(98)00041-X.

Puller SL, West J. Efficient retail pricing in electricity and natural gas markets. Am Econ Rev 2013;103(3):350-5. http://www.jstor. org/stable/23469756.

Real-time Coal Trade Price. Real-time coal trade price in different areas of China. 2017. http://www.meitanwang.com/meitan/ MeiTanJiaGe (in Chinese).

Saad W, Han Z, Poor HV, et al. Game-theoretic methods for the smart grid: an overview of microgrid systems, demand-side management, and smart grid communications. IEEE Signal Process Mag. 2012;29(5):86-105. doi:10.1109/MSP.2012.2186410.

Su W, Huang AQ. A game theoretic framework for a next-generation retail electricity market with high penetration of distributed residential electricity suppliers. Appl Energy. 2014;119(119): 341-50. doi:10.1016/j.apenergy.2014.01.003.

The State Council Information Office of the People's Republic of China. Enhanced Actions on Climate Change: China's Intended Nationally Determined Contributions. 2015. http://www.scio. gov.cn/xwfbh/xwbfbh/wqfbh/2015/20151119/xgbd33811/Docu ment/1455864/1455864.htm (in Chinese).

Tian R, Zhang Q, Wang G, et al. Study on the promotion of natural gas-fired electricity with energy market reform in China using a dynamic game-theoretic model. Appl Energy. 2017;185(2): 1832-9. doi:10.1016/j.apenergy.2014.01.003.

Wang G, Zhang Q, Li H, et al. Study on the promotion impact of demand response on distributed PV penetration by using noncooperative game theoretical analysis. Appl Energy. 2017;185(4): 1869-78. doi:10.1016/j.apenergy.2016.01.016.

Xiao B, Niu D, Guo X. Can natural gas-fired power generation break through the dilemma in China? A system dynamics analysis. J Clean Prod. 2016;137:1191-204. doi:10.1016/j.jclepro.2016. 07.198 .

Yang P, Tang G, Nehorai A. A game-theoretic approach for optimal time-of-use electricity pricing. IEEE Trans Power Syst. 2013;28(2):884-92. doi:10.1109/TPWRS.2012.2207134.

Zhai H, Rubin ES. Comparative performance and cost assessments of coal- and natural-gas-fired power plants under a $\mathrm{CO}_{2}$ emission performance standard regulation. Energy Fuels. 2013;27(8): 4290-301. doi:10.1021/ef302018v.

Zhang Q, McLellan BC, Tezuka T, et al. An integrated model for long-term power generation planning toward future smart electricity systems. Appl Energy. 2013;112(16):1424-37. doi:10.1016/j.apenergy.2013.03.073.

Zhao X, Wang J, Liu X, et al. China's wind, biomass and solar power generation: What the situation tells us? Renew Sustain Energy Rev. 2012;16(8):6173-82. doi:10.1016/j.rser.2012.07.020.

Zhao Y, Tang KK, Wang LL. Do renewable electricity policies promote renewable electricity generation? Evidence from panel 
data. Energy Policy. 2013a;62(5):887-97. doi:10.1016/j.enpol. 2013.07.072.

Zhao ZY, Yan H, Zuo J, et al. A critical review of factors affecting the wind power generation industry in China. Renew Sustain Energy Rev. 2013b;19(2):499-508. doi:10.1016/j.rser.2012.11.066.
Zhao ZY, Chen YL, Chang RD. How to stimulate renewable energy power generation effectively? Power generation industry in China lessons. Renew Energy. 2016;92:147-56. doi:10.1016/j. renene.2016.02.001. 